\title{
screams like home: A PHOTOBOOK PROJECT
}

\section{Thomas Lord}

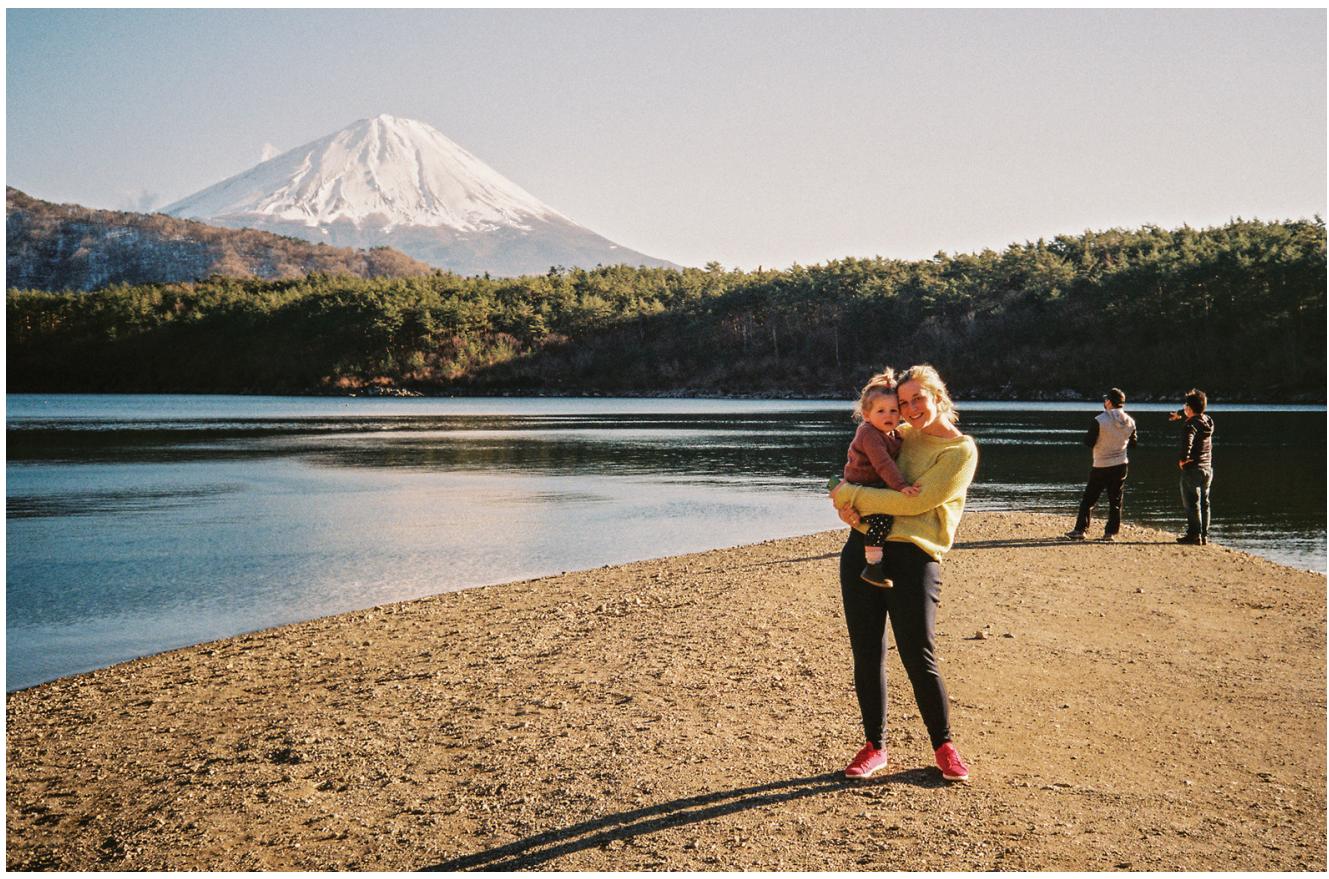

Figure I. Kat and Naomi reuniting with Fuji-San from Lake Saiko. Photograph:Thomas Lord.

In February 2020 I travelled with my wife Kat and our nearly two-year-old daughter Naomi to Yamanashi, Japan. Yamanashi is a landlocked prefecture most famous for its national parks and as the home of Mt Fuji. It is an area often bypassed by tourists and most commonly viewed at speed from the Shinkansen (from Tokyo to Kyoto). Our three weeks in Yamanashi were a chance to see old friends and reconnect with a place Kat and I used to call home. A place that for two years captured our hearts, allowed for intense focus and grounded me in a way that I thought was impossible.

As well as enjoying a family holiday I intended to create a body of work that would eventually turn into a book project. I wanted to explore the notion of déjà vécu ("already lived"), a phenomena I experienced during my first six months in Japan. It was an everyday occurrence for me, sometimes lasting up to several minutes at a time. You could say that I wanted to reconcile the vagaries of memory in an effort to allow for new ones.

Travelling with a toddler has its challenges. Rather than planning a structured schedule with desired shoots and locations, I approached the project with some naivety and a general curiosity. This way, I hoped that the everyday would organically build into something more than a typology of Japanese playgrounds. 


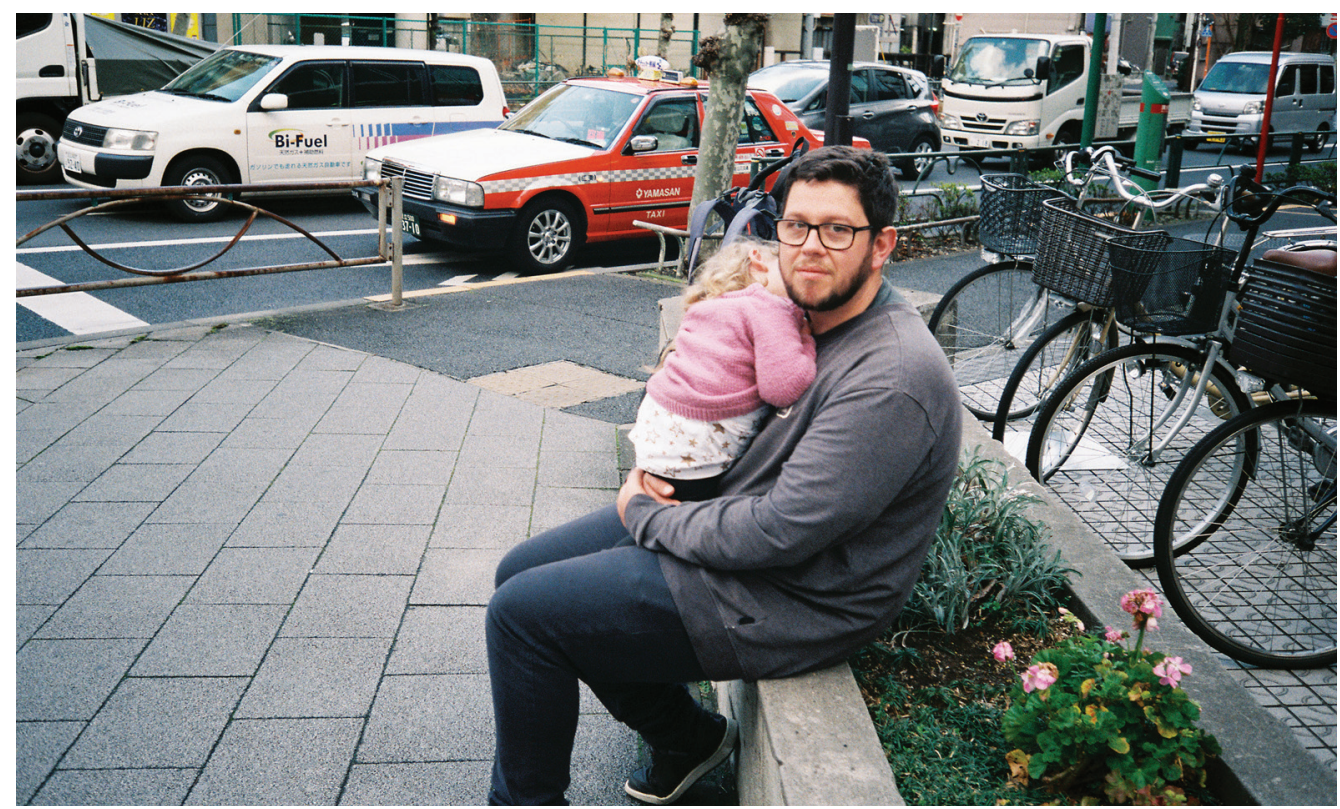

Figure 2. Stopping for unplanned naps even on busy street corners. Photograph: Kat Lord.

While Tokyo is an amazing city to start a holiday, for me it was always a weekend destination or transitional space. My initial feelings were frustration, in that I was wasting film on meaningless tourist images. I took comfort in something Paul Graham said in a conversation describing his process for shooting abroad in his New Europe series:

"I had to get the tourist out of my system; you have to get the sightseeing out the way, then get angry and frustrated with yourself. Photographs are everywhere and nowhere."'

Our opening weeks in the big city reintroduced familiar smells from neighbourhood izakayas and homely expressions of agreement and surprise. The sounds of pedestrian crossings, crows and trains passing meshed into a soundtrack I had been mourning for six years. The crows especially caught the interest of Naomi, who enjoyed mimicking them - sometimes directly back at them and sometimes to the surprise of the hotel receptionist.

Surrendering to the process and letting chance take control, I shot two films a day, 32 photographs, without trying to place them in any future context. Within my frame, naturally occurring orders began to reveal themselves. Enormous whale monuments (Figure 3 ) held up by poles evocative of the ancient trees scattered around temples; piles of discarded rubbish combined with fallen leaves that resemble the all-too-familiar shape of Fuji-san - a mountain worshipped from afar and seen by some as a female deity, with the chance to purify oneself and find happiness once climbed. ${ }^{2}$

Yamanashi provided a change of pace. Trains bursting at capacity were replaced by a small rental car, while empty villages superseded pedestrian crossings exceeding 2.4 million people a day. ${ }^{3}$ Days were spent retracing our walks to work, exploring mountainous temples and reuniting with old friends and colleagues.

Decaying tool sheds, Minobu incense and, of course, the ever-present crows all reminded me of what makes up the fabric of this place. A moss-ridden padlocked door (Figure 5), attached only with wire to a nearby tree, caught my eye. Exploring this scene further, I noticed that someone had failed to remove a resting ladder before cleaning the wall. A scene that could have easily belonged to one of many childhood trips to the Catlins; potentially one of the reasons why I find this place so comforting. 
Being removed from the big city also permitted Naomi to run around more and find her own curiosities (Figure 6). This invariably led to photo opportunities, including many of the images that are found in the final book. It became a collaboration of sorts, one that I was more willing to except now that the adjustment period was over. A period of giving up control to work closely with Naomi - whereas my practice before had been one of intention and sought solitude.

As well as following Naomi's intuition, I have to acknowledge the cats of Yamanashi. In Japanese folklore, cats sometimes appear as yōkai ("apparitions") and have protective powers while also symbolising good luck. I recall a moment of solitude within the hills that was interrupted by a feeling that something was watching me. A quick scout reveals nothing. However, casting my attention back to where I was photographing, a white cat now observes me. I'm frozen as we spend a few minutes looking at each other. I feel the urge to give a half-hearted bow, resulting in a quick nod; the cat responds with a slow blink. Effortlessly and in silence, the cat disappears behind an abandoned glasshouse. A few days later l've stopped to photograph a sign in the city. The sign depicts a bearded bear with glasses holding a toothbrush - a sign we used to joke about, as it vaguely resembled me. A snap on the phone and I'm about to leave - something is stopping me again. With one hand on the driver's door, I look up at the nearby apartments and spot a white cat watching me again. I smile, I nod and this time I ask to take its photo (Figure 9).

Less than a week after receiving my negatives back, I attended the PhotobookNZ masterclass at Massey University. Although I was going in fresh without a clear idea of the outcome, it was a great chance to speak with photographers, designers and publishers one-to-one about the trip and, more importantly, the images I came back with. The masterclass provided me with the time to handle books, think about layout and what kind of book I wanted my images to exist in. During an informal presentation, I was interrupted by a photographer who pointed out that I had described several images as "screaming like home." He was intrigued by this interpretation and so was I, as I couldn't recall using this explanation before. Using this phrase as a prospective title, I put several edits together and returned to Ōtepoti with multiple

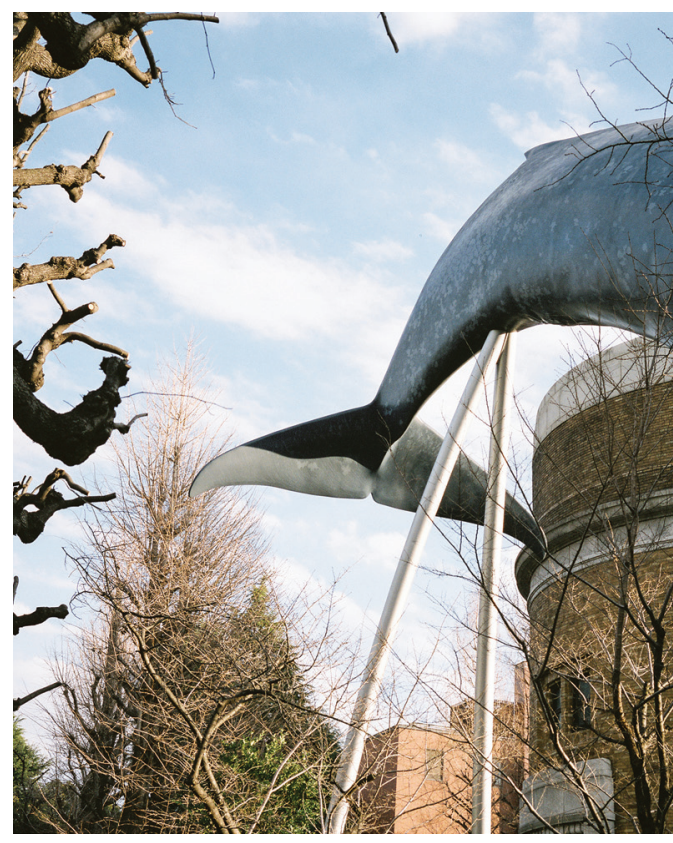

Figure 3. From screams like home book. Photograph:Thomas Lord.

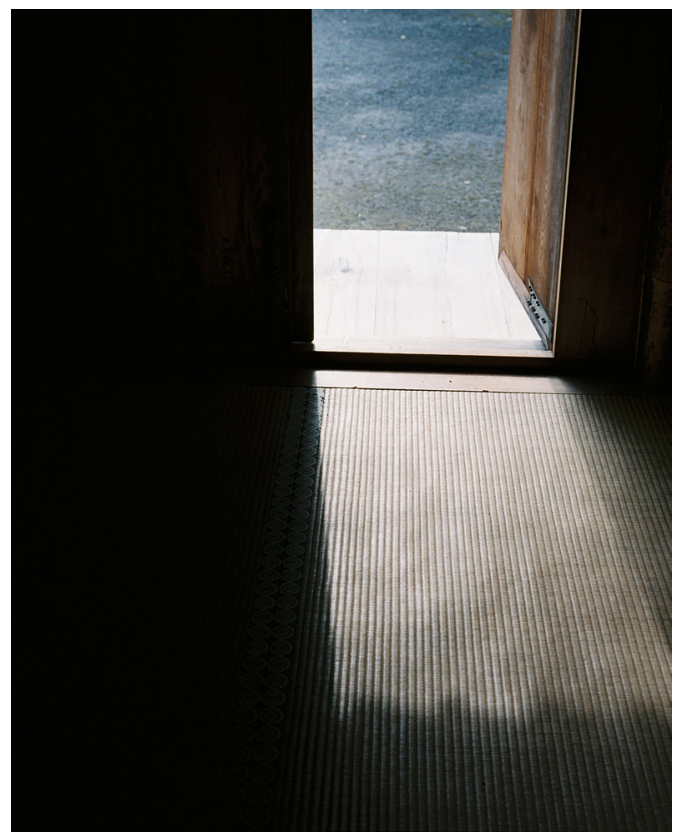

Figure 4. From screams like home book. Photograph:Thomas Lord. outcomes in mind. 

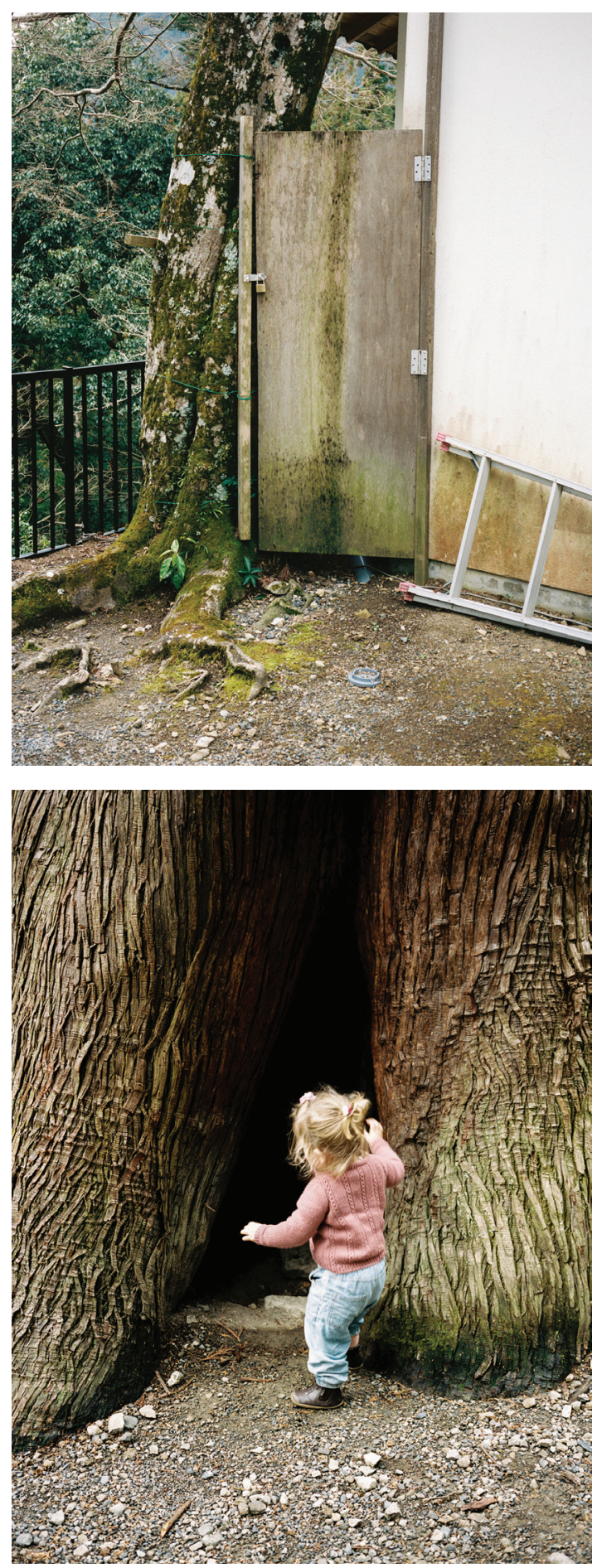

A fortnight later New Zealand was in alert-level 4 lockdown. During this time of heightened uncertainty (and internal ruminations on whether or not I should proceed with the book), our quotidian routine of walks around the block were a highlight - observing the seasons change, watching the different fungi appear and, of course, seeing which houses had a new teddy display. Walking as a family and stopping at whatever caught Naomi's attention felt strangely like our time in Japan. At night I would work on the book. This sequencing acted as another exploration or extension of my neighbourhood bubble. This was a comforting and methodical process which kept my mind away from the thought of potentially having left Japan for the last time.

There are two pieces of writing in the book. The first is a short excerpt from my 2012 diary and the second is "Tokyo is yours,"4 an essay by Rachel Hope Allan. Rachel's essay talks about her first impressions of Tokyo and the details which quickly made her fall in love with the city. This was a piece of writing about arriving in a new place - not about Yamanashi, but about Tokyo. At this point I decided on my layout and determined to split the book into halves, inverted at the centre with identical covers (Figure 13). I kept my original series of intimate, full-page-bleed Yamanashi images, while I generated a new sequence for Rachel's writing which consisted of smaller images from our initial days in Tokyo - a time when I was frustrated and confused about the project, a time when I was trying to find the familiar in the unfamiliar. Subtracting the lived experience, patterns began to emerge and I found a sequence that spoke directly to the emotions expressed in Rachel's writing, while also highlighting some of the contrasts inherent in my own experience.

screams like home is roughly A5 in size, which speaks to its intimacy while travelling through the images. It also reflects the size of a book you would find people reading on trains or in a convenience store. It has been met with curiosity, confusion and a sense that if you take away the occasional sign, this could be a book about anywhere. 

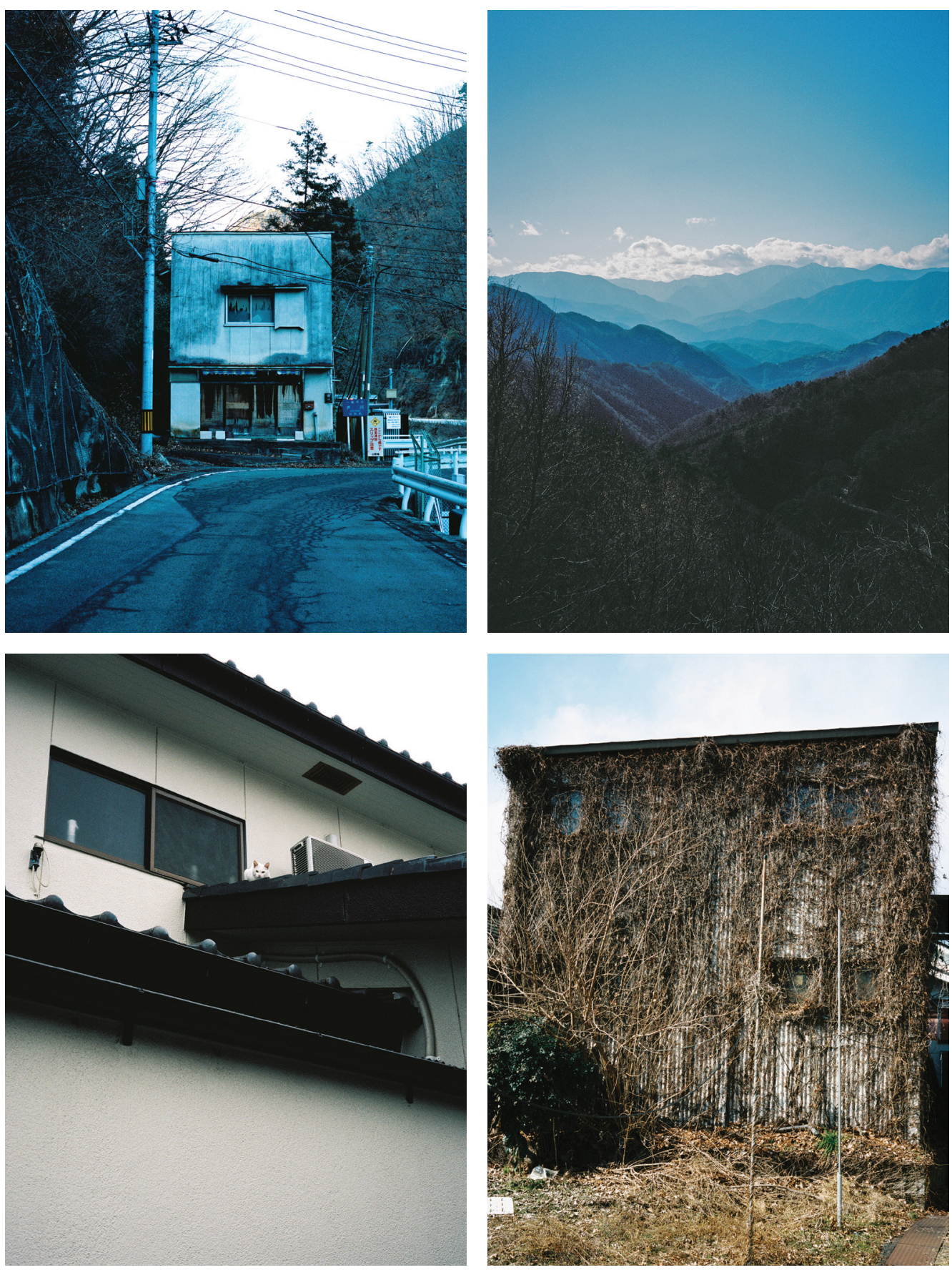

Previous page

Figure 5, 7, 8, 9, 10, 1 1, 12 \& 13. From screams like home book. Figure 6. Naomi exploring 1000 year old cedar tree. Photograph:Thomas Lord. Photographs:Thomas Lord 

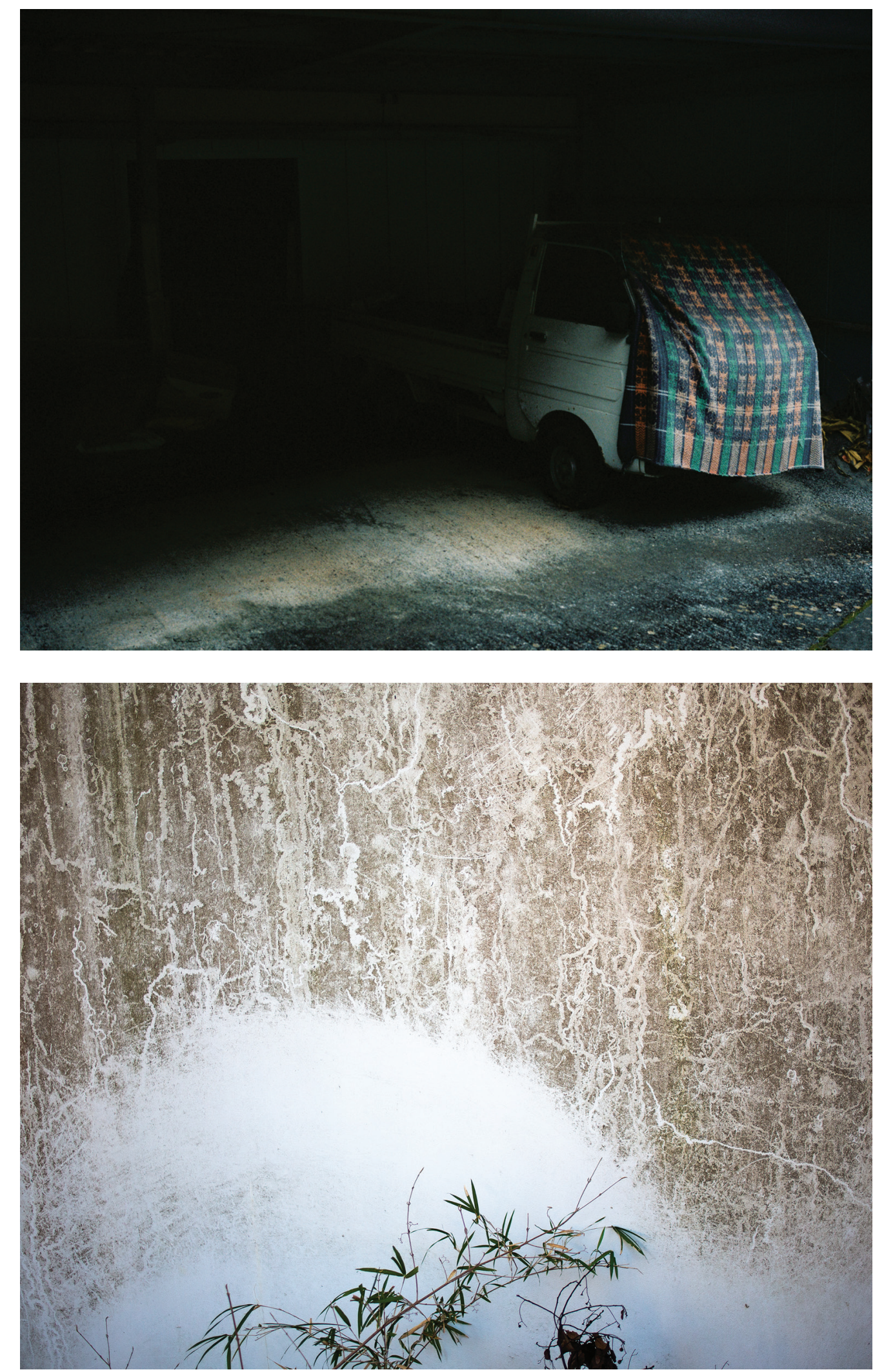

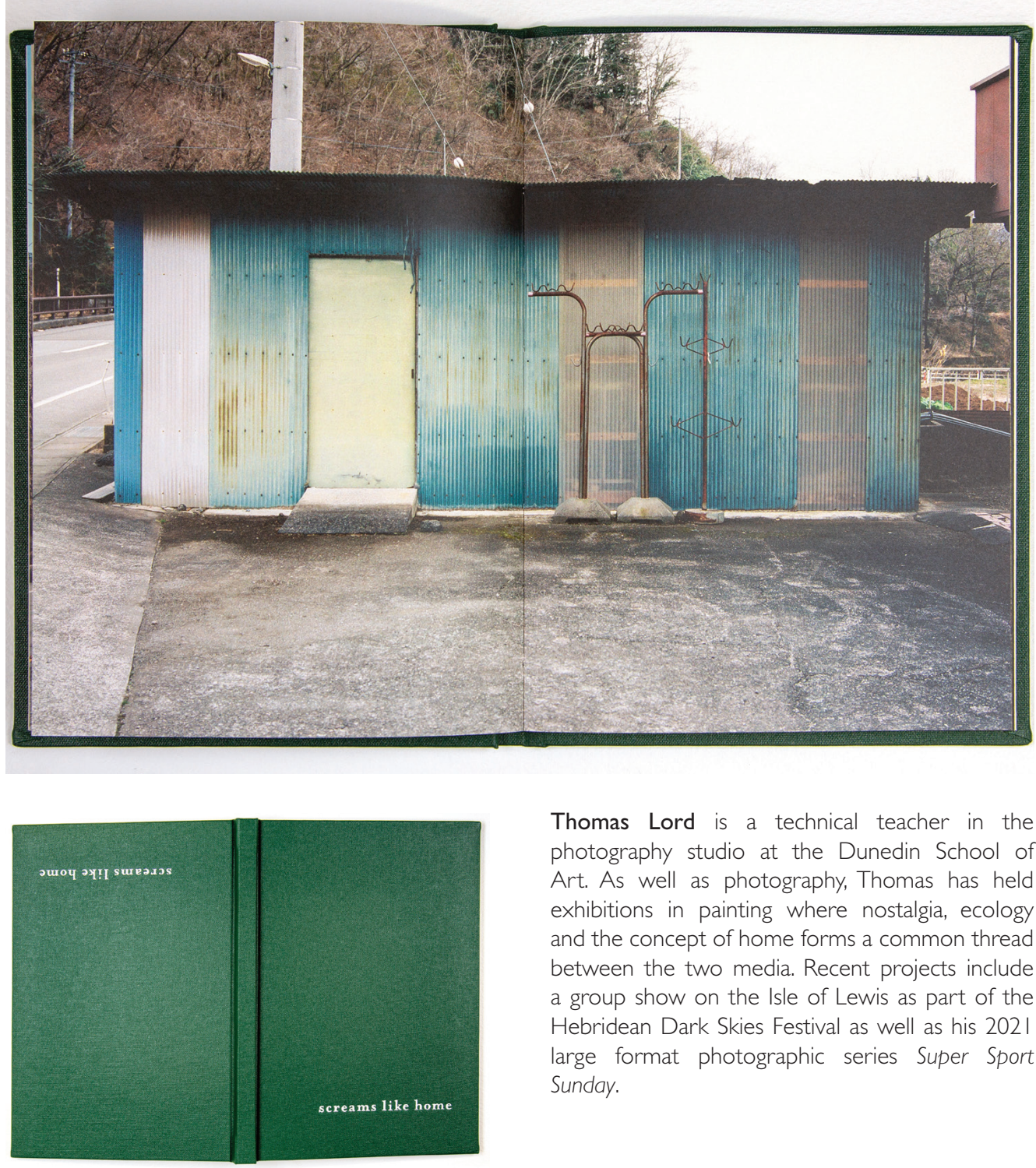

Thomas Lord is a technical teacher in the photography studio at the Dunedin School of Art. As well as photography, Thomas has held exhibitions in painting where nostalgia, ecology and the concept of home forms a common thread between the two media. Recent projects include a group show on the Isle of Lewis as part of the Hebridean Dark Skies Festival as well as his 2021 large format photographic series Super Sport Sunday.

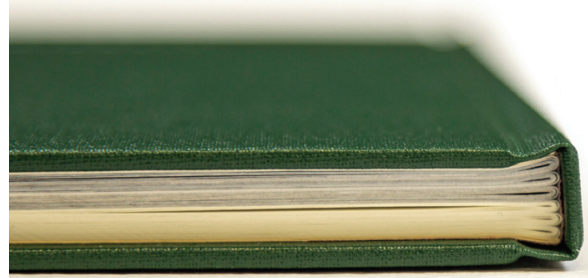

I Paul Graham, quoted in Andrew Wilson, Paul Graham (London: Phaidon, 1996).

2 UNESCO, "Fujisan, Sacred Place and Source of Artistic Inspiration," World Heritage List, https://whc.unesco.org/ en/list/I4I8/ (accessed 23 March 202I).

3 "Shibuya Crossing, the World's Busiest Crossing," Japan Rail Pass, 30 October 2020, https://www. jrailpass.com/blog/shibuya-crossing\#: : text=On\%20 average\%2C\%20over\%202.4\%20million,2\%2C500\%20 pedestrians\%20on\%20every\%20crossing (accessed 2 April 2021).

ISBN $9780473535957 / 2020$

$21 \times 14.8 \mathrm{~cm} / 96$ pages / 83 images /

Munken pure I30gsm paper / section bound /

4 Rachel Hope Allan, Tokyo is yours, screams like home (Dunedin:The Author, 2020). 